\title{
The Deviation and Consistence of Locative Words in Chinese and English from the Perspective of Intercultural Communication
}

\author{
Yanhong Liu \\ Academy of Humanities and Social Sciences \\ East China Jiaotong University \\ Nanchang, China 330013
}

\begin{abstract}
This paper takes "east, west, south, and north" in Chinese as the reference, and makes comparison with the corresponding English words in their differences and commonness, so as to grasp the "deviation" (different cultural characteristics) and the "consistence" (commonness) of locative worlds in Chinese and English, and thus to promote the smooth cross-cultural communication.
\end{abstract}

Keywords-intercultural communication; east; north; deviation; consistence

\section{INTRODUCTION}

Language is a kind of psychological activity of human being that established by the people through long social practice. It is a symbolic system for people to exchange ideas and carry on thinking. In the process of social development, language has accumulated the deposition of national, social and historical development. As the main form of language structure, vocabulary is bound to be branded by the national cultural psychology in its emotional attachment. In crosscultural communication, only a few words in different languages that express the same thing have the equal meaning and are in consistence in culture, but most of them are different. Locative word is one example.

\section{DEVIATION IN WORD ORDER}

According to the study of cognitive psychology, there are two different space worlds: physical space and cognitive space. Physical space is the world that objectively exists. It is a threedimensional scene, unique, unchanging and omnidirectional world. While cognitive space is the spatial world in which physical space is perceived by human perception organs. In the same physical space, the cognitive space is different from the different viewpoint or direction. (Fang Jingmin, 2002) ${ }^{[1]}$. Locative words in both Chinese and English are closely related to their ideas and religious beliefs.

When the locative words "east, south, west and north" appear at the same time, the word order in Chinese and English are different. In Chinese, the word order is "east, west, south and north" or "east, south, west and north". According to our search in "The National Committee Language Balanced Corpus of Modern Chinese", the word order of "east, west, south and north" appears 27 times, but the word order of "east, south, west and north" only appears 7 times. Both of these two orders place "east" in the front. However, the word order in English is mainly "north, south, east and west", which place north in the first place ${ }^{[2]}$.

The reasons are closely related to the living environment and lifestyle of China and Britain. China is a traditional agricultural society. Chinese people take sun as their reference, go to work at sunrise and go home at sunset. As the rising position of the sun, "east" naturally occupies a vital position in life. Sun brings life and hope to human, so people worship the sun greatly, and Huaxia is the nation named after sun. According to Jing Yien (1998), the original meaning of "Hua" is the name of sun, and therefore Hua tribe is the tribe of sun. Xia people were born from Hua. There are many different writing methods of "Xia" in Jin language, and the commonness lies in that there is always a people lifted the sun with his head or hand. Therefore, Xia inherited Hua tribe's name of sun tribe ${ }^{[3]}$. Facing the worship object, they worshiped every day, so as to express their piety and respect. There is a record of worship sun in oracle bone inscription:

Zhen made sacrifice with three cows to the "East Mother". ("Collections of Oracle Bone Inscription" 14339)

Make sacrifice to the "East Mother"... three jia and three zhuo (three pigs). ("Collections of Oracle Bone Inscription" 14341)

According to the research by the scholars, "East Mother" is Xihe that gave birth to ten suns, also known as god of sun; therefore "make sacrifice to East Mother" means worship sun with fire.

From the word "East Mother", we see the relationship between the east and the sun. In "Huananzi, Astronomy", "Southeast" is called "Yang tian", from which we can see that the solar movement is a link between the east and the south. The Chinese worship the sun and naturally attach great importance to the "east", which is closely related to the sun. Therefore, when the four directions are arranged in parallel, it is naturally to place the predomination "east" in the first place.

There are many evidences of using "east, west, south and north" more than "east, south, west and north". In "The 
National Committee Language Balanced Corpus of Modern Chinese", the occurrence of "east" is 1037 , west is 1154 , south is 935 and north is 875 . The frequency of "east" and "west" is far more than "south" and "north". From the study of locative words of other minority groups, we can find that there are "east and west", but no "south and north" in some minority languages like Hani, Pumi, Mengwa, Ronghong Qiang and so on. It is obvious that "east and west" are easier to be recognized in four directions. More interesting is that in Korean, which also belongs to Chinese-character cultural circle, most words are opposite in east and west, but no words is opposite in south and north. Therefore, east and west are more important than north and south no matter for the Han nationality itself, the minority language, or compared with the related language. So it is reasonable to place "east and west" in the front. In the two directions of "east and west", because east is closely related to the sun that worshiped by people, it is naturally to place east in front of west, and thus make it the first among four directions.

In English, north is placed in the first among four directions, which is related to Britain's geographical position. Britain is a typical island country that there is not more than 120 kilometers from any point in the island to the sea, and the coastline is 8000 kilometers. In such geographical environment, maritime transportation is well developed. Seafaring requires navigation. Although the sun can help to determine the direction, the position of sun in four seasons is changing, and the only constant reference is the North Star that point to the north. Therefore, there is the arrangement of north, south, east and west.

From the extended meaning of the word "North Star", we can also infer the dominant position of North in the four directions. The word "North Star" also can be called "Polaris, North Star, Pole Star, loadstar" in English. Among them, the word "loadstar" not only has the meaning of "North Star", but also means governing principle. "Principle" plays an important role in people's actions, so north is the first among four directions.

The using frequency of four words east, west, south and north is different. According to the data of Corpus of Contemporary American English, the occurrence of east is 68320 , west is 71268 , south is 80368 and north is 70715 . The occurrence of north and south is higher than east and west, and the combination of north and south (1559 times) is also more than east and west(1110 times). Words that are frequently used are generally more important and closely related to life, and it makes sense to put such words in the first place.

The reference point used in the definitions of four directions "east, west, south and north" is also different in Chinese and English. The definitions of these four locative words in "Modern Chinese Dictionary" are as following:

East: One of the four main directions where the sun rises. down

West: One of the four main directions where the sun goes

South: One of the four main directions, the right side of a person facing the sun in the morning.
North: One of the four main directions, the left side of a person facing the sun in the morning.

However, the definitions in "Longman Dictionary of Contemporary English" are as following:

East: The direction which is on the right of a person facing the north.

West: The direction which is on the left of a person facing the north.

South: The direction which is down from the center of the equator.

North: The direction which is up from the center of the equator.

From the definition of the Chinese and English dictionaries, we can see that "east" and "west" are positioned by the sun in Chinese; while north is regarded as the reference point of "east" and "west" in English. The direction with obvious reference point is naturally easy to be grasp and become the common word, and thus it occupies the front place among four directions, such as "east and west" in Chinese and "north" in English.

In fact, from the language of the ethnic minorities in the north of China, the order of placing north and south in the front in English could better reflect the ancient idea of people. According to Arden's (2001) study, it is not the truth that taking the direction of sunrise as east and the direction of sunset as west since the beginning of direction from the experience of the ancestors of the northern nationalities. From the Altai language family in the north, the term "east" and "west" has gone through four phases: the direction of sunrise and sunset $\rightarrow$ front and back $\rightarrow$ south and north $\rightarrow$ east and west ${ }^{[4]}$. That is to say, it is in the final stage that the sunrise direction is called the east, and the sunset direction is called the west, and "south and north" are prior to "east and west".

\section{THE CONSISTENCY OF "EAST" AND "NORTH"}

Although the languages of different nationalities carry different cultures and ways of thinking, human thinking has something in common that people of different nationalities can communicate and cooperate with each other smoothly. Therefore, in addition to the above deviation of locative words, there is also something in common, which can also be called "consistency". If people can accurately understand the cultural consistency, it can promote the smooth cross-cultural communication, and enhance the sense of belonging of foreign language learners.

\section{A. The Consistency of East in Chinese and English in the Concept of "New Life"}

The East is the place where the sun rises. It is a place to bring light and warmth to people, as well as to bring spring and vitality to the earth. Nature is connected with life. The eastern wind (spring breeze) is known as "Xie feng" later. "Xie" has the meaning of consistent (copulation). In the concept of ancient people, wind is formed under the combination of heaven and earth, and it is the behavior of creators gave birth 
to all things. In "Springs and Autumns of Master Lv Meng Chun", it is recorded that "in this month, the heaven descends and earth rises that heaven and earth are in copulation, and thus grass and tree become prosperous." In the eyes of ancient people, spring wind is the product of heaven and earth, and thus east wind is called "Xie feng"[5]. With the reproductive concept of natural Yin and Yang, not only heaven and earth are in copulation, birds and beasts are mating, and male and female also need to get together to gave birth to the new generation, therefore, "east" has the meaning of "life".

Easter, developed by East, is also related to "new life". In ancient times, Easter commemorated the spring and the dawn goddess Eostre. The Nordic people always celebrated the Eostre's Festival in the spring and celebrated the rebirth of all things in nature. Later, Christians linked the sunrise to the resurrection of Jesus and their spiritual rebirth, and began celebrating Easter ${ }^{[6]}$. Therefore, in the cultural concept of "new life", Chinese is similar to English.

Even the "Easter Eggs", which was eaten at Easter, is interlinked with the ancient Chinese concept of egg worship. In "Shi Ji Biographic Sketch of Yin", it recorded that "Yin Qi's mother is Jian Di, the daughter of You Song, and the imperial concubine of $\mathrm{Di} \mathrm{Ku}$. When the three were bath, they saw a bird egg fell. Jian Di ate the egg and then gave birth to Qi." Being pregnant without a husband is the reflection of worshiping egg. This concept still exists in the some wedding and pregnant customs. A German scholar, Hans Bidderman, had pointed out that, "the legend that the world was born in a raw egg is not purely a creation myth of Orpheus [the night with black wings accepted the proposal of wind, gave birth to an egg and then Eros or Phanes came into being], it also existed in the culture of Polynesia, Japan, Peru, India, Phoenicia, China, Finland and Slavic, etc." ${ }^{[7]}$ Some Western folklore experts even believe that the cosmic egg myth is evidence that the Central American traditional culture and the Pacific Islands and Southeast Asia are closely related.

"As a matter of fact, the egg represents the primordial bud, and the later world is born from it. The egg represents the integrity contained in the shell, suggesting that the creation is well planned from the beginning. In the Christian world, chickens hatch from eggs, symbolizing the rise of Jesus from the dead, and the white egg shell symbolizes purity and perfection." (Hans Bidderman, 2000) ${ }^{[8]}$ Therefore, when Jesus was reborn, it would be most appropriate to eat eggs that represent the new life.

\section{B. The Consistency of North in Chinese and English in the Concept of "Land of Death"}

The south is closely related to the sun, the place of light and life, and thus the north is the land of darkness. "On Sun" in Volume 11 of "Lun Heng" said that, "the north place is where Yin existed". "Zanggong" in Volume 48 of "Hou Han Shu", Li Xian made notes that, "people prefer Yang but hate Yin. The north is the Yin place. So the losing part always called north." Since the north is the land of darkness, it naturally is the place where death is and the place where all things are hidden. "Shang Shu Da Zhuan" said that, "What is north place? It is the direction that all things are hidden." In ancient times, most dead people were buried in the north of his residential place, and some were even buried with head to the north. In "Li Ji Tan Gong Xia", "buried in the north is the general custom, as the north is quiet and secluded" Kong Yingda said that, "it is said that a person who is buried in the north and has his/her head toward the north, can make his/her soul rest because the place is quiet" The practices of bury people in the north have been mentioned many times in ancient books. In the 29th year of Xiang Gong in "Zuo Zhuan", "Qi people buried Zhuang Gong in the north place." The most famous tombs in history are probable in the North Mang Mountain at the back of Luoyang. Many people from the imperial families and senior officials have been buried here since the Eastern Han Dynasty, and thus made it famous. The ancient people even called the magic of meeting the dead "north sea magic". The Yin and darkness of the north place can be regarded as the place name of tomb, which served as the guarantee of "north sea magic". "9]

According to Encyclopedia Britannica Online, the etymology of "North" is interpreted as: probably from "nerteros" of Greek, meaning lower, infernal. Hell is the place where people go after death. Therefore, north in Chinese and English are consistent in the sense of "land of death".

It is not only in Chinese and English that north is related to "land of death", which is the same in Egypt. It is well known that Pyramid was the tomb of the Egyptian Pharaohs. Although the base of Pyramid is positioned along the meridian, each side of the square base faces four basic directions (east, south, west, and north). In fact, the entrance to Pyramid is always in the north. ${ }^{[10]}$

Why did they make such arrangements when built Pyramid? The "authoritative" translator of pyramid texts R. O. Faulkner wrote, "As we all know, the ancient Egyptians were very interested in the stars not only for their practical purposes... they also carved star charts and code in their coffin and tomb... they regard the stars as gods or the spirits who have ascended to heaven after their death."[11] The American archaeologist Martin Gisle reiterated the fact that by mentioning King Khufu Pyramid, he said, "Accurate positioning can only be achieved by celestial bodies." The accuracy of Pyramid was surprising, with an average deviation of only 1.8 minute of arc. This deviation is minimal for such a large memorial tower. Celesial body or the object that used as target cannot be large solar disk or moon disk (as assumed by Gisle), but it must be a beam of light, which strongly suggests that it is a star. ${ }^{[12]}$ As we have mentioned above, the star that play a guiding role to people is the "North Star", therefore, the burial door was opened in the north, so that his soul could ascend into the heaven.

\section{CONCLUSION}

The national cultural psychology of a language is like a dark underground river, surging in the strata of national consciousness. As long as we pay attention to the "deviation" and "consistence" of the language and culture of Chinese and English in language research, and explore the cultural psychology of the nation intentionally, we can better understand and use the language, and achieve the purpose of 
using Chinese correctly and understanding the essence of culture on the basis of our own understanding.

\section{REFERENCES}

[1] Fang Jingmin. A Cognitive Study of Spatial Orientation Reference System in Modern Chinese [D]. Shanghai: Shanghai Normal University, 2002.

[2] Wang Linlin. A Study on the Word Order Difference of Chinese and English Locative Words [J]. Overseas Chinese Education, 2004 (4).

[3] Jing Yien. The Worship of Sun and the Origin of Huaxia Nation [J]. Folk Literature Forum, 1998 (1)

[4] A'er Dingfu. On Forming, Developing and Evolving of Space Concepts of Northern Nationalities the View — on Location in the Ancient Mongolia Cultural History [J]. Journal of Central University For Nationalities. 2002(1).

[5] Yang Lin. Chinese Vocabulary and Huaxia Culture [M]. Beijing: Language Press, 1996.

[6] Yang Youfang. English Bible Etymology [M]. Chengdu: Sichuan People's Publishing House, 2002.

[7] Liao Mingjun. Cultural Interpretation of Reproductive Worship [M]. Nanning: Guangxi People's Publishing House, 2006.

[8] Hans Bidderman, Liu Yuhong, etc. translate. Dictionary of Symbolism [M]. Guilin: Lijiang Press, 2000.

[9] Zhou Shuanlong ed. Rethinking on Tradition and Recognizing Mountain Tai $[\mathrm{M}]$. Beijing: Thread-Binding Books Publishing House, 2010.

[10] Robert Bauval. The Orion Mystery [M]. Nanjing: Jiangsu People's Publishing House, 2011.

[11] R. O. Faulkner. The King and the Star-Religion in the Pyramid [J]. Journal of Near Eastern Studies, 25.

[12] M. Isler. Journal of the American Center for Egyptian studies [J]. 1989 (26). 